\title{
PENGARUH FAKTOR-FAKTOR MOTIVASI DITINJAU DARI SISI FINANSIAL, PSIKOLOGI, DAN SOSIAL TERHADAP PRESTASI KERJA KARYAWAN PADA PT. GELORA DJAJA SURABAYA
}

\author{
Lilik Nurcholidah \\ Prodi Manajemen, Fakultas Ekonomi, Universitas Islam Lamongan \\ Jl. Veteran No.53A Lamongan \\ Telp. ( 0322 ) 324706, Faks. ( 0322 ) 324706 \\ Email :jpim@unisla.ac.id
}

\begin{abstract}
ABSTRAK
Penelitian ini bertujuan untuk mengetahui apakah faktor-faktor motivasi ditinjau dari sisi financial, psikologi, dan social berpengaruh secara simultan terhadap prestasi kerja karyawan, untuk mengetahui apakah faktor-faktor motivasi dari sisi financial, psikologi, dan social berpengaruh secara parsial terhadap prestasi kerja karyawan, dan untuk mengetahui faktor-faktor motivasi (financial, psikologi, dan social) manakah yang lebih dominan mempengaruhi prestasi kerja karyawan pada PT. Gelora Djaja Surabaya. Sejalan dengan tujuan tersebut dan hipotesis penelitian maka penelitian ini dilaksanakan dengan menggunakan metode deskripsi kuantitatif. Hasil analisa regresi berganda $Y=2,827+$ $0,243 X_{1}+0,185 X_{2}+0,432 X_{3}$. Hasil t $t_{1}$ (finansial) 2,882, $t_{2}$ (psikologi) 2,122, $t_{3}$ (sosial) $4,388>t_{\text {tabel }} 2,05553$. Perhitungan $F_{\text {hitung }} 12,213>F_{\text {tabel }} 2,98$. Dari analisa tersebut dapat disimpulkan bahwa faktor social yang mempunyai pengaruh yang lebih dominan terhadap prestasi kerja karyawan, faktor-faktor motivasi ditinjau dari sisi financial, psikologi, dan social berpengaruh secara parsial terhadap prestasi kerja karyawan dan faktor-faktor motivasi ditinjau dari sisi financial, psikologi, dan social berpengaruh secara simultan terhadap prestasi kerja karyawan pada PT. Gelora Djaja Surabaya.
\end{abstract}

Kata kunci: Faktor Finansial, Psikologi, Sosial dan Prestasi Kerja

\section{PENDAHULUAN}

Menurut Edy Sutrisno (2011), sumber daya manusia adalah suatu sumber daya yang sangat dibutuhkan oleh suatu organisasi. Sebab, sumber daya manusia adalah sumber yang berperan aktif terhadap jalannya suatu organisasi dan proses pengambilan keputusan. Pengambilan suatu keputusan terbaik yang dihasilkan oleh suatu sumber daya manusia menunjukkan kinerja seseorang dan kemampuannya untuk menganalisis suatu masalah dalam lingkup kerja dan jabatannya.

Menurut Siagian (2005), motivasi merupakan keadaan kejiwaan yang mendorong, mengaktifkan atau menggerakkan dan motif itulah yang mengarahkan dan menyalurkan perilaku, sikap, dan tindak tanduk seseorang yang selalu dikaitkan dengan pencapaian tujuan, baik tujuan organisasi maupun tujuan pribadi masing-masing anggota organisasi.

Motivasi untuk bekerja ini sangat penting bagi tinggi rendahnya produktivitas perusahaan. Tanpa adanya 
motivasi dari para karyawan untuk bekerja sama bagi kepentingan perusahaan, maka tujuan yang telah ditetapkan tidak akan tercapai. Sebaliknya, apabila terdapat motivasi yang tinggi dari para karyawan maka hal ini merupakan suatu jaminan atas keberhasilan perusahaan dalam mencapai tujuannya (Gitosudarmo, 2005).

Oleh karena itu, manajer harus selalu menimbulkan motivasi kerja yang tinggi kepada karyawannya guna melaksanakan tugas-tugasnya. Sekalipun harus diakui bahwa motivasi bukan satusatunya faktor yang mempengaruhi tingkat prestasi kerja seseorang. Ada faktor lain yang ikut mempengaruhi seperti pengetahuan, sikap, kemampuan, pengalaman, dan persepsi peranan.

Prestasi kerja merupakan sebagai hasil kerja yang telah dicapai seseorang dari tingkah laku kerjanya dalam melaksanakan aktivitas kerja (Edy Sutrisno, 2011). Apabila terjadi penurunan prestasi kerja karyawan sering diakibatkan oleh hilangnya motivasi dan semangat kerja karyawan. Motivasi muncul dikarenakan adanya kebutuhan yang harus dipenuhi oleh individu dan kelompok karena adanya perpaduan antara motivasi dan kemampuan diri tiap orang sehingga dicapai prestasi kerja yang tinggi.

Agar tidak terjadi penurunan prestasi kerja karyawan maka perusahaan harus bisa meningkatkan kembali prestasi dan semangat kerja karyawan. Mungkin dengan memberikan perhatian seperti memberi tunjangan, promosi jabatan, memberikan fasilitas yang nyaman dan memberikan dorongan atau masukan agar karyawannya untuk lebih maju. Perhatian tersebut sangat mempengaruhi kinerja karyawannya.

Rumusan masalah pada penelitian ini adalah:

1) Apakah faktor-faktor motivasi ditinjau dari sisi financial, psikologi, dan social berpengaruh secara simultan terhadap prestasi kerja karyawan pada PT. Gelora Djaja Surabaya?

2) Apakah faktor-faktor motivasi ditinjau dari sisi financial, psikologi, dan social berpengaruh secara parsial terhadap prestasi kerja karyawan pada PT. Gelora Djaja Surabaya?

3) Faktor-faktor motivasi (financial, psikologi, dan sosial) manakah yang mempunyai pengaruh paling dominan terhadap prestasi kerja karyawan pada PT. Gelora Djaja Surabaya?

Tujuan dari penelitian ini adalah:

1) Untuk mengetahui apakah faktor-faktor motivasi ditinjau dari sisi financial, psikologi, dan social berpengaruh secara simultan terhadap prestasi kerja karyawan pada PT. Gelora Djaja Surabaya. 
2) Untuk mengetahui apakah faktor-faktor motivasi ditinjau dari sisi financial, psikologi, dan social berpengaruh secara parsial terhadap prestasi kerja karyawan pada PT. Gelora Djaja Surabaya.

3) Untuk mengetahui faktor-faktor motivasi (financial, psikologi, dan sosial) manakah yang paling dominan dalam mempengaruhi prestasi kerja karyawan pada PT. Gelora Djaja Surabaya

\section{LANDASAN TEORI}

Financial berarti mempelajari kemampuan individu, bisnis dan organisasi untuk mengelola, meningkatkan, mengalokasi juga menggunakan sumberdaya moneter yang sejalan dengan waktu serta menghitung risiko dan menentukan prospek. Financial juga dapat berarti administrasi yang mengelola urusan keluar masuknya uang pada sebuah institusi atau lembaga.

Tujuan lembaga keuangan yaitu melancarkan pertukaran produk, menghimpun dana dari masyarakat dalam bentuk simpanan dan menyalurkan dalam bentuk pinjaman, dan menghimpun dana dari pihak yang memiliki kelebihan dana dan menyalurkan kepada pihak yang kekurangan dana.
Psikologi adalah ilmu yang mempelajari tingkah laku manusia (Singgih Dirgagunarsa, 2009:03). Macammacam psikologi dan penerapannya yaitu :

1. Pembagian berdasarkan objek yang diselidiki

a. Psikologi umum ialah psikologi yang menyelidiki dan mempelajari kegiatan-kegiatan atau aktivitas psikis manusia pada umumnya yang dewasa, yang normal dan yang beradab.

b. Psikologi khusus ialah psikologi yang menyelidiki dan mempelajari segi-segi kekhususan dari aktivitas psikis manusia.

2. Pembagian berdasarkan kegunaannya

a. Psikologi teoretis ialah ilmu jiwa yang mempelajari gejala-gejala kejiwaan untuk gejala-gejala itu sendiri.

b. Psikologi praktis ialah ilmu jiwa yang mempelajari segala sesuatu tentang jiwa untuk digunakan dalam praktik.

Tujuan mempelajari psikologi adalah untuk memperoleh pemahaman tentang gejala-gejala jiwa dan pengertian yang lebih sempurna tentang tingkah laku sesame manusia pada umumnya dan anakanak pada khususnya, untuk mengetahui perbuatan-perbuatan jiwa serta kemampuan jiwa sebagai sarana untuk 
mengenal tingkah laku manusia atau anak, dan untuk mengetahui penyelenggaraan pendidikan dengan baik.

Menurut Plato dan Aristoteles, social adalah hubungan jiwa antara manusia yang satu dengan manusia yang lain, yang disebabkan adanya bakat social pada manusia atau insting social pada manusia. Plato pun berpendapat bahwa masyarakat yang baik pun harus terdiri dari manusia-manusia yang merupakan 3 lapisan yaitu:

a. Lapisan manusia yang masing-masing terdiri dari manusia yang dikendalikan oleh pikirannya yang kuat.

b. Lapisan manusia yang masing-masing terdiri dari manusia yang dikendalikan oleh kemauannya yang kuat.

c. Lapisan manusia yang masing-masing terdiri dari manusia-manusia yang dikendalikan oleh keinginannya yang kuat.

Menurut Edy Sutrisno prestasi kerja adalah sebagai hasil kerja yang telah dicapai seseorang dari tingkah laku kerjanya dalam melaksanakan aktivitas kerja.

Menurut Byar dan Rue dalam Sutrisno (2011:151) ada dua faktor yang mempengaruhi prestasi kerja yaitu :

1. Faktor individu

a. Usaha (effort) yang menunjukkan sejumlah sinergi fisik dan mental yang digunakan dalam menyelenggarakan gerakan tugas.

b. Abilities yaitu sifat-sifat personal yang diperlukan untuk melaksanakan suatu tugas.

c. Role/task perception yaitu segala perilaku dan aktivitas yang dirasa perlu oleh individu untuk menyelesaikan suatu pekerjaan.

2. Faktor lingkungan

a. Kondisi fisik

b. Peralatan

c. Waktu

d. Material

e. Pendidikan

f. Supervise

g. Desain organisasi

h. Pelatihan

i. Keberuntungan

Menurut Hani Handoko (2012), penilaian prestasi kerja adalah proses melalui mana organisasi-organisasi mengevaluasi atau menilai prestasi kerja karyawan. Kegunaan penilaian prestasi kerja (Hani Handoko, 2012:135)yaitu :

a. Perbaikan prestasi kerja.

b. Penyesuaian-penyesuaian kompensasi.

c. Keputusan-keputusan penempatan.

d. Kebutuhan-kebutuhan latihan dan pengembangan.

e. Perencanaan dan pengembangan karier.

f. Penyimpangan-penyimpangan proses staffing. 
g. Ketidak-akuratan informasional.

h. Kesalahan-kesalahan desain pekerjaan.

i. Kesempatan kerja yang adil.

j. Tantangan-tantangan eksternal.

\section{METODE PENELITIAN}

Dalam penelitian ini sesuai dengan tujuan yang hendak di capai, yakni pengaruh faktor-faktor motivasi ditinjau dari sisi financial, psikologi, dan social terhadap prestasi kerja karyawan pada PT. Gelora Djaja Surabaya maka jenis penelitian ini menggunakan penelitian deskripsi kuantitatif.

\section{A. Teknik penarikan sampel}

1. Populasi

Adapun populasi dalam penelitian ini adalah seluruh karyawan bagian operasionalpada PT. Gelora Djaja Surabaya dengan jumlah sekitar 30 orang.

2. Sampel

Sampel adalah bagian dari jumlah populasi. Sampel yang ada didalam penelitian ini adalah 30 orang responden dari anggota populasi.

3. Teknik sampling

Teknik sampling yang digunakan dalam penelitian ini adalah probability sampling yaitu teknik pengambilan sampel yang memberikan peluang yang sama bagi setiap anggota populasi untuk dipilih menjadi anggota sampel.

\section{B. Jenis data yang digunakan dalam penelitian ini adalah:}

1. Data Primer

Data Primer dalam penelitian ini diperoleh secara langsung dari PT. Gelora Djaja Surabaya dan wawancara terhadap karyawan yang bersangkutan.

2. Data Sekunder

Data sekunder diperoleh dari dokumentasi dan Library Research pada PT. Gelora Djaja Surabaya.

Dalam penelitian ini yang menjadi variabel bebas adalah $\mathrm{X}_{1}$ (faktor finansial) yaitu faktor yang berhubungan dengan jaminan serta kesejahteraan karyawan, yang meliputi system dan besarnya gaji, jaminan social, tunjangan, fasilitas yang diberikan dan promosi, kemudian $\mathrm{X}_{2}$ (faktor psikologi) yaitu faktor yang berhubungan dengan kejiwaan karyawan yang meliputi minat, ketenteraman kerja, sikap, bakat, keterampilan dan $X_{3}$ (faktor sosial) yaitu faktor yang berhubungan dengan interaksi social antar karyawan maupun karyawan dengan atasan. Variabel terikat adalah prestasi kerja karyawan (Y) yaitu hasil upaya seseorang yang ditentukan oleh kemampuan 
karakteristik pribadinya serta persepsi terhadap perannya dalam pekerjaan itu (Byars dan Rue, 1984).

Metode analisa data yang penulis gunakan dalam penelitian ini adalah uji validitas, uji reliabilitas, regresi linier berganda, korelasi, uji t, dan uji F.

\section{Uji validitas}

Uji validitas digunakan untuk mengetahui kevalidan dari variabel independen terhadap variabel dependen (Arikunto, 2010:213) yang dirumuskan sebagai berikut :

$\mathrm{R}_{\mathrm{xy}}=\frac{n(\Sigma x y)-(\Sigma x)(\Sigma y)}{\left.\sqrt{\left\{n\left(\Sigma x^{2}\right)-(\Sigma x)^{2}\right.}\right\} /\left\{n\left(\Sigma y^{2}\right)-(\Sigma y)^{2}\right\}}$

Dimana :

$\mathrm{r}_{\mathrm{xy}}$ :Korelasi antara variabel $\mathrm{x}$ dan $\mathrm{y}$

$\mathrm{n}$ :Jumlah responden

$\Sigma \mathrm{x}$ :Jumlah skor yang diperoleh dari responden yang diuji

$\Sigma y: J u m l a h$ skor total seluruh item dari responden yang diuji

\section{Uji reliabilitas}

Uji reliabilitas digunakan untuk mengetahui kerealan atau nyata dari variabel independen terhadap variabel dependen (Soekidjo Notoatmodjo, 2010:168) yang dirumuskan sebagai berikut :

$\mathrm{r}=\left(\frac{n}{n-1}\right)\left(1-\frac{\Sigma \sigma t^{2}}{\sigma t^{2}}\right)$

Dimana :

r :Reliabilitas yang dicari n :Jumlah responden

$\Sigma \sigma \mathrm{t}^{2}:$ Jumlah varians skor tiap-tiap item

$\sigma \mathrm{t}^{2} \quad$ :Varians total

\section{Regresi linier berganda}

Regresi linier berganda digunakan untuk mengetahui besarnya pengaruh masing-masing variabel bebas terhadap variabel terikat (Sugiyono, 2013:261) yang dirumuskan sebagai berikut :

$Y=a+b_{1} X_{1}+b_{2} X_{2}+b_{3} X_{3}$

Dimana :

Y :Prestasi kerja

a :Konstanta

$b_{1}, b_{2}, b_{3}:$ Koefisien regresi

$\mathrm{X}_{1} \quad$ :Faktor finansial

$\mathrm{X}_{2} \quad$ :Faktor psikologi

$\mathrm{X}_{3} \quad$ :Faktor sosial

\section{Korelasi}

Korelasi digunakan untuk mengetahui keeratan suatu hubungan terhadap variabel bebas terhadap variabel terikat (Sugiyono, 2013:228) yang dirumuskan sebagai berikut :

$\mathrm{r}=\frac{n \Sigma x y-(\Sigma x)(\Sigma y)}{\sqrt{\left\{n \Sigma x^{2}-(\Sigma x)^{2}\right\}\left\{n \Sigma y^{2}-(\Sigma y)^{2}\right\}}}$

Dimana :

r $\quad$ :Koefisien korelasi

n :Banyaknya responden

$\mathrm{x}$ :Variabel bebas (financial, psikologi, sosial)

y :Variabel terikat (prestasi kerja) 
Tabel 3.1

Interprestasi Koefisien Korelasi

\begin{tabular}{|c|c|}
\hline $\begin{array}{c}\text { Interval } \\
\text { Koefisien }\end{array}$ & $\begin{array}{c}\text { Tingkat } \\
\text { Hubungan }\end{array}$ \\
\hline $0,00-0,199$ & Sangat rendah \\
$0,20-0,399$ & Rendah \\
$0,40-0,599$ & Sedang \\
$0,60-0,799$ & Kuat \\
$0,80-1,000$ & Sangat kuat \\
\hline
\end{tabular}

\section{Uji t}

Uji $t$ digunakan untuk mengetahui apakah variabel independen berpengaruh secara parsial terhadap variabel dependen (Sugiyono, 2010:80) yang dirumuskan sebagai berikut :

$\mathrm{T}_{\text {hitung }}=\frac{r \sqrt{n-2}}{\sqrt{1-r^{2}}}$

Dimana :

t :Uji korelasi (nilai $\mathrm{t}_{\text {hitung }}$ )

r :Nilai koefisien korelasi

n :Jumlah responden

Adapun criteria pengujian uji $\mathrm{t}$ (uji parsial) adalah :

- Jika $\mathrm{t}_{\text {hitung }}>\mathrm{t}_{\text {tabel}}, \mathrm{H}_{0}$ ditolak, $\mathrm{H}_{1}$ diterima maka hipotesis diterima

- Jika $t_{\text {hitung }}<\mathrm{t}_{\text {tabel }}, \mathrm{H}_{0}$ diterima, $\mathrm{H}_{1}$ ditolak maka hipotesis ditolak

Gambar 3.1

Daerah penerimaan dan penolakan hipotesis berdasarkan uji $\mathbf{t}$

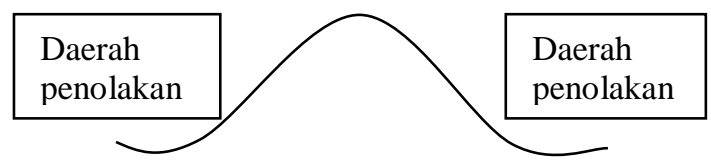

Daerah penerimaa $y$ $-t_{\text {hitung }}-t_{\text {tabel }} \quad t_{\text {tabel }} \quad t_{\text {hitung }}$

6. Uji F

Uji $F$ digunakan untuk mengetahui apakah variabel independen berpengaruh secara simultan terhadap variabel dependen (Sugiyono, 2010:81) yang dirumuskan sebagai berikut :

$\mathrm{F}_{\text {hitung }}=\frac{R^{2}(k-1)}{\left(1-R^{2}\right) /(n-k)}$

Dimana :

$\mathrm{F}_{\mathrm{h}} \quad$ :F hitung

$\mathrm{R}^{2} \quad$ :Koefisien determinasi

n :Jumlah responden

k :Jumlah seluruh variabel

Adapun criteria pengujian uji f (uji simultan) adalah :

- Jika $\mathrm{F}_{\text {hitung }}>\mathrm{F}_{\text {tabel }}, \mathrm{H}_{0}$ ditolak, $\mathrm{H}_{1}$ diterima maka hipotesis diterima

- Jika $\mathrm{F}_{\text {hitung }}<\mathrm{F}_{\text {tabel }}, \mathrm{H}_{0}$ diterima, $\mathrm{H}_{1}$ ditolak maka hipotesis ditolak

Gambar 3.2

Daerah penerimaan dan penolakan hipotesis berdasarkan uji $\mathbf{F}$

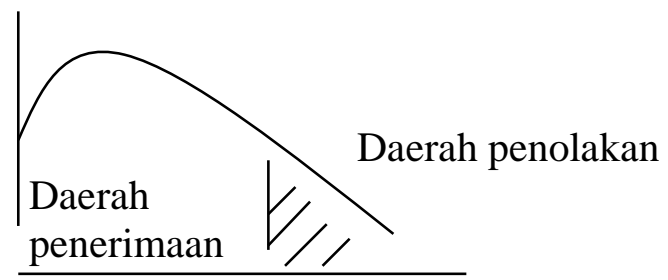

$\mathrm{F}_{\text {tabel }} \quad \mathrm{F}_{\text {hitung }}$ 


\section{HASIL}

\section{Tabel 5.5}

Hasil validitas data

\begin{tabular}{|c|c|c|c|c|}
\hline Indicator soal & $\begin{array}{l}\text { No } \\
\text { soal }\end{array}$ & r hitung & $r$ tabel & keterangan \\
\hline \multirow[t]{5}{*}{$\begin{array}{l}\text { Faktor financial } \\
\left(\mathrm{X}_{1}\right)\end{array}$} & 1 & 0,812 & 0,3494 & Valid \\
\hline & 2 & 0,539 & 0,3494 & Valid \\
\hline & 3 & 0,732 & 0,3494 & Valid \\
\hline & 4 & 0,761 & 0,3494 & Valid \\
\hline & 5 & 0,666 & 0,3494 & Valid \\
\hline \multirow[t]{5}{*}{$\begin{array}{l}\text { Faktor } \\
\text { psikologi }\left(\mathrm{X}_{2}\right)\end{array}$} & 1 & 0,641 & 0,3494 & Valid \\
\hline & 2 & 0,676 & 0,3494 & Valid \\
\hline & 3 & 0,722 & 0,3494 & Valid \\
\hline & 4 & 0,727 & 0,3494 & Valid \\
\hline & 5 & 0,560 & 0,3494 & Valid \\
\hline \multirow[t]{4}{*}{$\begin{array}{l}\text { Faktor social } \\
\left(\mathrm{X}_{3}\right)\end{array}$} & 1 & 0,711 & 0,3494 & Valid \\
\hline & 2 & 0,883 & 0,3494 & Valid \\
\hline & 3 & 0,898 & 0,3494 & Valid \\
\hline & 4 & 0,829 & 0,3494 & Valid \\
\hline \multirow[t]{4}{*}{$\begin{array}{l}\text { Prestasi kerja } \\
\text { (Y) }\end{array}$} & 1 & 0,612 & 0,3494 & Valid \\
\hline & 2 & 0,544 & 0,3494 & Valid \\
\hline & 3 & 0,732 & 0,3494 & Valid \\
\hline & 4 & 0,539 & 0,3494 & Valid \\
\hline
\end{tabular}

Dari tabel 5.5 di atas terlihat bahwa semua indicator menunjukkan hasil yang signifikan dan menunjukkan bahwa $r_{\text {hitung }}$ $>r_{\text {tabel }}$ sehingga dapat disimpulkan semua item pertanyaan dinyatakan valid.

Tabel 5.6

Hasil uji reliabilitas

\begin{tabular}{|c|l|c|c|c|}
\hline No & variabel & $\begin{array}{l}\text { Nilai } \\
\text { alpha }\end{array}$ & $\begin{array}{l}\text { Standar } \\
\text { reliabilitas }\end{array}$ & $\begin{array}{l}\text { keterang } \\
\text { an }\end{array}$ \\
\hline 1 & $\begin{array}{l}\text { Faktor } \\
\text { financial }\end{array}$ & 0,746 & 0,60 & Reliabel \\
\hline 2 & $\begin{array}{l}\text { Faktor } \\
\text { psikologi }\end{array}$ & 0,707 & 0,60 & Reliabel \\
\hline
\end{tabular}

\begin{tabular}{|c|l|c|c|c|}
\hline 3 & $\begin{array}{l}\text { Faktor } \\
\text { social }\end{array}$ & 0,845 & 0,60 & Reliabel \\
\hline 4 & $\begin{array}{l}\text { Prestasi } \\
\text { kerja }\end{array}$ & 0,773 & 0,60 & Reliabel \\
\hline
\end{tabular}

Dari tabel 5.6 diatas menunjukkan bahwa semua variabel mempunyai nilai alpha yang cukup tinggi yaitu diatas 0,60 sehingga dapat disimpulkan bahwa semua variabel bebas dan terikatnya reliabel.

\section{PEMBAHASAN}

Dari uji regresi linear sederhana, didapatkan suatu persamaan regresi sebagai berikut $\mathrm{Y}=2,827+0,243 \mathrm{X}_{1}+$ $0,185 \mathrm{X}_{2}+0,432 \mathrm{X}_{3}$. Sehingga dapat ditarik kesimpulan bahwa nilai $\mathrm{a}=2,827$ merupakan konstan yang berarti bahwa apabila variabel bebas (financial, psikologi, dan sosial) dalam penelitian pengaruhnya $=0$, maka hasil dari prestasi kerja karyawan adalah sebesar 2,827. $b_{1}=$ 0,243 , artinya apabila faktor financial dinaikkan 1 satuan/1 unit maka prestasi kerja karyawan akan naik/bertambah sebesar 0,243 dengan asumsi variabel lain yang mempengaruhi dianggap konstan. $\mathrm{b}_{2}=0,185$, artinya apabila faktorpsikologi dinaikkan 1 satuan/1 unit maka prestasi kerja karyawan akan naik/bertambah sebesar 0,185 dengan asumsi variabel lain yang mempengaruhi dianggap konstan. $\mathrm{b}_{3}=0,432$, artinya apabila faktor social dinaikkan 1 satuan/1 unit maka prestasi kerja karyawan akan naik/bertambah 
sebesar 0,432 dengan asumsi variabel lain yang mempengaruhi dianggap konstan.

Dari perhitungan uji korelasi diperoleh sebesar 0,765. Artinya tingkat hubungan antara faktor financial, psikologi, dan social terhadap prestasi kerja adalah kuat. Hasil penelitian uji $\mathrm{t}$ menunjukan bahwa $t_{1}$ (finansial) sebesar $2,882, \mathrm{t}_{2}$ (psikologi) sebesar $2,122, \mathrm{t}_{3}$ (sosial) sebesar 4,388 lebih besar dari nilai $\mathrm{t}_{\text {tabel }} 2,05553$ dengan $\mathrm{df}=\mathrm{n}-\mathrm{k}-1=30-3-1=$ 26 , pada taraf signifikasi $\alpha=0,05(0,05 / 2=$ 0,025) maka hipotesis Ho ditolak dan $\mathrm{Ha}$ diterima. Dengan demikian kesimpulannya adalah ada pengaruh yang signifikan antara variabel bebas (financial, psikologi, dan sosial) terhadap prestasi kerja karyawan pada PT. Gelora Djaja Surabaya.

Dalam perhitungan secara bersama-sama yang menggunakan uji f diperoleh nilai $F_{\text {hitung }}$ sebesar 12,213, sedangkan $\mathrm{F}_{\text {tabel }} 2,98$ dengan $\mathrm{df}_{1}=\mathrm{k}-1=4$ $1=3$ dan $\mathrm{df}_{2}=\mathrm{n}-\mathrm{k}=30-4=26$, pada taraf signifikan 0,05. Karena $F_{\text {hitung }}>F_{\text {tabel }}$ maka Ho ditolak dan $\mathrm{Ha}$ diterima, sehingga teruji bahwa secara bersama-sama ada pengaruh yang signifikan antara variabel bebas (financial, psikologi, dan sosial) terhadap prestasi kerja karyawan pada PT. Gelora Djaja Surabaya.

\section{Simpulan}

Berdasarkan hasil penelitian dan pembahasan dapat disimpulkan sebagai berikut:

Variabel bebas faktor financial, psikologi dan social mempunyai pengaruh yang simultan terhadap prestasi kerja karyawan pada PT. Gelora Djaja Surabaya. Hal ini bisa dibuktikan dengan nilai $F_{\text {hitung }}$ $>\mathrm{F}_{\text {tabel }}$ yaitu 12,213> 2,98.

Dari hasil uji t (parsial) diperoleh nilai $\mathrm{t}$ hitung faktor financial $(2,882)$, faktor psikologi $(2,122)$, dan faktor social $(4,388)$ lebih besar dari nilai t tabel sebesar 2,05553. Variabel bebas faktor financial, psikologi, dan social mempunyai nilai $\mathrm{t}$ hitung > t tabel yang berarti variabel bebas mempunyai pengaruh yang signifikan terhadap prestasi kerja pada PT. Gelora Djaja Surabaya.

Dari nilai regresi $\mathrm{Y}=2,827+0,243$ $\mathrm{X}_{1}+0,185 \mathrm{X}_{2}+0,432 \mathrm{X}_{3}$ diperoleh koefisien regresi variabel faktor social sebesar 0,432. Dan hasil uji t diperoleh $t$ hitung faktor financial $(2,882)$, faktor psikologi (2,122), dan faktor social (4,388). Dengan demikian dapat ditarik kesimpulan bahwa variabel yang paling dominan mempengaruhi prestasi kerja adalah faktor social.

\section{Saran}

\section{SIMPULAN DAN SARAN}


Dari apa yang telah penulis lakukan pada penelitian ini, maka terdapat saran yang perlu disampaikan kepada pemimpin PT. Gelora Djaja Surabaya antara lain :

Pemimpin harus memberikan motivasi yang tinggi dan memberikan dukungan kepada karyawannya agar dapat bekerja lebih baik lagi, diharapkan hubungan pemimpin dengan karyawan, karyawan dengan pimpinan dan karyawan dengan karyawan berjalan dengan baik, dan terakhir diharapkan pemimpin dapat memberikan contoh yang baik terhadap karyawannya seperti sifat, tingkah laku dan perbuatan agar karyawan tersebut mempunyai perilaku yang baik.

\section{DAFTAR PUSTAKA}

Ahmadi, Abu. 2009. Psikologi Umum. Jakarta : Rineka Cipta.

As'ad. 2005. Psikologi dalam Perusahaan. Jakarta : Aneka Cipta.

Handoko, T. Hani. 2012. Manajemen Personalia dan Sumberdaya Manusia. Yogyakarta : BPFE.

Notoatmodjo, Soekidjo. 2010. Metodologi Penelitian. Jakarta : Rineka Cipta.

Rivai, Veithzal. 2005. Manajemen Sumber Daya Manusia untuk Perusahaan. Jakarta : RajaGrafindo Persada.

Siagian, Sondang P. 2006. Manajemen Sumber Daya Manusia. Jakarta : Bumi Aksara.

Dirgagunarsa, Singgih. 2009. Pengantar Psikologi Terapan. Jakarta : Rineka Cipta.
Sutrisno, Edy. 2011. Manajemen Sumber Daya Manusia. Jakarta : Kencana.

Sugiyono. 2013. Statistika untuk Penelitian. Bandung : Alfabeta. 